\title{
Characterizing a scientific elite: the social characteristics of the most highly cited scientists in environmental science and ecology
}

\author{
John N. Parker $\cdot$ Christopher Lortie $\cdot$ Stefano Allesina
}

Received: 4 November 2009/Published online: 6 May 2010

(C) The Author(s) 2010. This article is published with open access at Springerlink.com

\begin{abstract}
In science, a relatively small pool of researchers garners a disproportionally large number of citations. Still, very little is known about the social characteristics of highly cited scientists. This is unfortunate as these researchers wield a disproportional impact on their fields, and the study of highly cited scientists can enhance our understanding of the conditions which foster highly cited work, the systematic social inequalities which exist in science, and scientific careers more generally. This study provides information on this understudied subject by examining the social characteristics and opinions of the $0.1 \%$ most cited environmental scientists and ecologists. Overall, the social characteristics of these researchers tend to reflect broader patterns of inequality in the global scientific community. However, while the social characteristics of these researchers mirror those of other scientific elites in important ways, they differ in others, revealing findings which are both novel and surprising, perhaps indicating multiple pathways to becoming highly cited.
\end{abstract}

Keywords Highly-cited · Ecology $\cdot$ Environmental science $\cdot$ Stratification Scientific elite $\cdot$ Citation

J. N. Parker $(\bowtie)$

National Center for Ecological Analysis and Synthesis, University of California,

Santa Barbara, 735 State Street, Suite 300, Santa Barbara, CA 9310, USA

e-mail: parker@nceas.ucsb.edu

C. Lortie

York University, Toronto, ON, Canada

e-mail: christopher@onepoint.ca

S. Allesina

University of Chicago, Chicago, IL, USA

e-mail: allesina@nceas.ucsb.edu 


\section{Introduction}

Background

Most scientific publications are authored by a small proportion of researchers, and the majority of citations reference a relatively small pool of articles (Lotka 1926; Dennis 1955; Price 1963; Cole and Cole 1973). Surprisingly however, very little is known about the characteristics of highly cited scientists. This is unfortunate as there are important reasons for studying this population. First, in the institution of science the tail wags the proverbial dog. Highly cited researchers wield a vastly disproportionate influence on their fields, and knowing something about their social characteristics provides insights into the conditions that foster highly cited work. Second, the study of highly cited scientists can also enhance our understanding of the systematic inequalities that exist in science in such areas as the under representation of women and non-Western researchers. Third, there is a certain voyeuristic appeal to the study of highly cited scientists. The achievements of eminent scientists offer exemplars and benchmarks by which the rest of us can gauge our own career trajectories and successes (Hermanowicz 1998, 2005). In this study, we examine the social characteristics of the most highly cited scientists in environmental science and ecology.

The study of highly cited researchers began with the work of Garfield (1981), and has continued based on data from Thomson Scientific's Web of Science. Citations are generally assumed to be an indicator of the quality or impact of a given research publication (Smith 1981). While citation counts are far from perfect indicators of scientific quality (MacRoberts and MacRoberts 1986, 1996; Warner 2000), they remain among the most used indicators of scientific impact and are correlated with other forms of scientific recognition (Garfield and Malin 1968; Garfield 1973, 1992; Cole and Cole 1973). Further, while it is certainly the case that research is cited for reasons other than quality, this argument is difficult to maintain when leveled at citation elites. As operationalized by Thompson Scientific, highly cited scientists comprise the top $0.1 \%$ most cited researchers in their field. Clearly, the work of these individuals is having a disproportional impact on science, regardless of the quality of any particular publication. This group of elite researchers serves as the focus of this study.

Despite more than 30-years of research, the social characteristics of highly cited researchers remain poorly understood. Their geographic distribution has received the most attention. For instance, McIntosh (1989) found that the majority of the authors of 80 'citation classics' in ecology were from North America and Western Europe. More recently, Batty (2003) found that $40 \%$ of highly cited scientists in 14 fields were concentrated in 10 institutions, 9 of which were located in the United States. Across all 21 disciplinary categories covered by Thompson Scientific the proportion of highly cited scientists in the U.S. ranges between 40 and 90\% (Basu 2006). Some research has also been conducted to determine the age at which highly cited scientists produce their most cited papers. Garfield (1981) found an average age of between 37 and 50 years among the thousand most highly cited scientists in all fields between the years 1965 and 1978. Biomedical researchers tend to produce their most highly cited articles between the ages of 31 and 35 (Falagas et al. 2008). Only two studies have examined the gender composition of highly cited scientists. Garfield (1981) found that women accounted for only $2.3 \%$ of the world's highly cited scientists (1965-1978). More recently, Trifunac (2006) found that women accounted for only $4 \%$ of highly cited scientists in earthquake engineering, but 
noted that the study sample size $(n=51)$ was too low to allow for meaningful generalizations.

These findings are compelling, suggesting that highly cited scientists tend to be North American, male, and of middle age. However, much more work is needed to test whether these generalizations hold across disciplines and to uncover the social characteristics of highly cited scientists in more meaningful detail. The development of field-level information is particularly critical as citation practices vary significantly across disciplines. It is also important to expand the suite of social characteristics under consideration to include such factors as demographic attributes, work habits and resources, and research foci. Furthermore, research indicating relationships between non-work related lifestyle choices (e.g. marriage, number of children; see e.g. Long and Fox 1995) on scientific productivity and research quality highlights the need to incorporate other such non-work related lifestyle considerations in the study of citation elites. Finally, given controversies over the use of citations to quantify scientific quality, consideration of the opinions of highly cited scientists regarding the institution of citations counts and their experiences with the peer review system also merits attention. This study contributes to the development of a more nuanced and systematic understanding of the social characteristics of highly cited scientists by examining these issues among the $0.1 \%$ most highly cited environmental scientists and ecologists. In the next section we develop a number of well-grounded predictions about this group based on previous research examining highly cited scientists and other scientific elites.

\section{Predictions}

\section{Demographic characteristics and lifestyle choices}

Based on previous work (Garfield 1981; Batty 2003; Trifunac 2006; Basu 2006), we expect these scientists to be based almost exclusively in North America and Western Europe and to be predominantly male. Given that scientists in other fields tend to publish their most highly cited research early in their careers (Falagas et al. 2008; Garfield 1981), the lag between publication and citation accrual, and that we are examining highly cited scientists within a broad 30-year period (more on this below), we also expect most respondents to be in middle to late career stage and between the ages of 50 and 70 years old. Additionally, Grim (2008) recently tested the relationship between non-work related lifestyle choices and scientific accomplishment among Czech ecologists, finding increased levels of beer consumption to be associated with lower numbers of publications, total citations, and citations per paper. Thus, we expect that this group will drink little on average, and will drink less than Grim's (significantly less cited and productive) Bohemian and Moravian samples.

\section{Work habits and resources}

Given the importance of accumulative advantage for becoming a scientific elite (Merton 1968; Zuckerman 1996) and the homogeneity of their professional origins and the caliber of institutions in which they work (Zuckerman 1996; Collins 1998; Hermanowicz 1998; Batty 2003), we expect this group to have uniformly large laboratories. Furthermore, because achieving highly cited status is likely based at least in part on being highly productive, ${ }^{1}$ we expect this group to work longer hours than their less cited colleagues and

\footnotetext{
1 A relationship verified at the national level (Basu 2006).
} 
to spend more time on research relative to service related activities. Finally, given the success of their research programs we expect this group to have consistently high levels of extramural funding. Several caveats are anticipated: First, US scientists are expected to be significantly better funded than non-US scientists. Second, we expect a significant, negative relationship between respondent's age and (a) total work hours, (b) the amount of time spent on research relative to service related activities, and (c) their levels of extramural funding. The latter caveats are based on previous research indicating that once ne plus ultra status has been achieved scientific elites tend to move away from active research and turn to more service-oriented work (e.g. serving on foundation boards and review committees), and to engage in noblesse oblige wherein they begin using their scientific capital to forward their protégé's careers rather than their own (Zuckerman 1996, pp. 178-183; Collins 1998, p. 71; Hackett 2005).

\section{Research foci, perspectives on citations and experiences with peer review}

We predict that these scientists will prefer research driven by theoretical concerns rather than social benefits as scientific reputations are typically founded on contributions to ongoing scientific debates (Hagstrom 1965; Kuhn 1962, 1977). Additionally, on the basis of past research (Hargens and Schuman 1990) we expect this group to believe that citations accurately measure scientific quality, and that their most highly cited papers are their most important contributions to their fields. Moreover, given that research specialization leads to increased scientific productivity (Leahey 2006, 2007; Leahey et al. 2008), and being highly productive increases one's chances of being highly cited, we expect these scientists to focus on a narrow set of research questions or issues. Finally, given their exceptional successes we expect that they fare well in peer review assessments.

\section{Data and methods}

Respondents were identified using the highly cited researchers listed in the area of environmental science and ecology (Thompson Scientific's ISIHighlyCited.com). Thompson Scientific identifies highly cited researchers by first considering all articles in their database in rolling, 20 year time intervals. Three such periods have been analyzed (1981-1999; 1983-2002; 1984-2003). Each article in the dataset (all three periods) is then assigned to one of the 21 broad disciplinary categories used by ISIHighlyCited.com (see Appendix 1 for details on the list of topics and journals included in the area of environment and ecology). Individual records are then created for all authors on each article. An article with $n$ number of authors will thus have $n$ number of individually indexed names developed for it. Citations to each article from any other article in Thompson Scientifics' citation databases are then counted, and each author credited with the total number of citations. Thus, in the case of an article with three authors receiving 50 citations, each author will be credited 50 citations. The total number of citations for each unique author is then summed, yielding their total number of citations across all articles in that research area. Individual researchers are then ranked according to their total number of citations. Beginning with the most highly cited researchers, Thompson Scientific editors use a variety of methods to confirm the publication and citation pattern for each highly cited author. Editors then work to contact each highly cited researcher and ask them to provide a copy of his/her curriculum vitae and related information for inclusion in ISIHighlyCited.com's database. 
An online survey was conducted from November 10th through December 31st, 2008, based on the ISI list of the most highly cited scientists in environmental science and ecology. Our sampling frame included all 345 scientists listed as highly cited in this area across all three periods analyzed by ISIHighlyCited.com. As the goal of this article is to examine the social characteristics of currently active, highly cited researchers, it was essential to select only those individuals still active in research. To do so, we first searched for all 345 highly cited individuals at their home institution as listed on ISIHighlyCited.com. Upon confirming their status as active researchers at each institution, we included them in the sampling frame. For those individuals whose affiliation could not be confirmed, we engaged in extensive internet searches to determine their current location and status as active researchers. In doing so, we noted all available email addresses for each potential survey respondent. Of the original 345 highly cited researchers, 306 were confirmed as active as evidenced through either the existence of active faculty web pages at their home institution as listed by ISIHighlyCited.com, or through subsequent internet searches (10 of those not confirmed as active researchers were confirmed as having died since their highly cited work was published). Having determined our total sampling frame, we then sent out three email requests to participate in the survey (an initial invitation to participate, with two reminders at 2 week intervals). Of the 306 individuals to whom invitations were sent, 12 responded that they were currently in the process of retiring and thus were not within our sampling frame. Another 13 of our requests were 'bounced' by the mail system, indicating an invalid email address, and 10 individuals who did respond were dropped from consideration as they reported working fewer than $30 \mathrm{~h}$ per week. Subtracting retirees, these exclusion classes, the total number of valid potential respondents dropped to 271 . We received a total of 124 valid survey responses, for an overall response rate of $45.7 \%$. This response rate is on par with similar surveys (Small 2004), and from 52 to $82 \%$ higher than is typical for internet-based surveys (Sills and Song 2002). (See Appendix 2 for a copy of the survey questionnaire.)

\section{Results}

Demographic characteristics and lifestyle choices

We gathered information on respondents' geographic distribution, gender, drinking habits, and age (Fig. 1a-d). The geographic distribution of highly cited researchers in environmental science and ecology is extremely skewed. Almost $65 \%$ work in the United States, while the inclusion of Canadian researchers brings the total up to $71 \%$. More than $93 \%$ work in North America and Western Europe. Of the remaining nine countries, only two (Australia and Israel) contained more than $1 \%$ of the world's highly cited researchers in this research area during this period. ${ }^{2}$

Using online queries and first names, we were able to determine the gender of 339 of the total 345 highly cited scientists. The vast majority $(92.8 \%)$ were men. Women accounted for $5.5 \%$ of the total. The gender of $1.7 \%$ of researchers could not be determined due to their use of initials rather than first names. Even assuming that women are more likely to

\footnotetext{
2 Thomson Scientific unifies author names only after the list of the most highly cited scientists has been calculated. It is thus possible that spelling of 'difficult' non-English names may challenge citation attribution in some cases. However, it is unlikely that this would substantially affect the geographic distribution of highly cited researchers as measured here.
} 


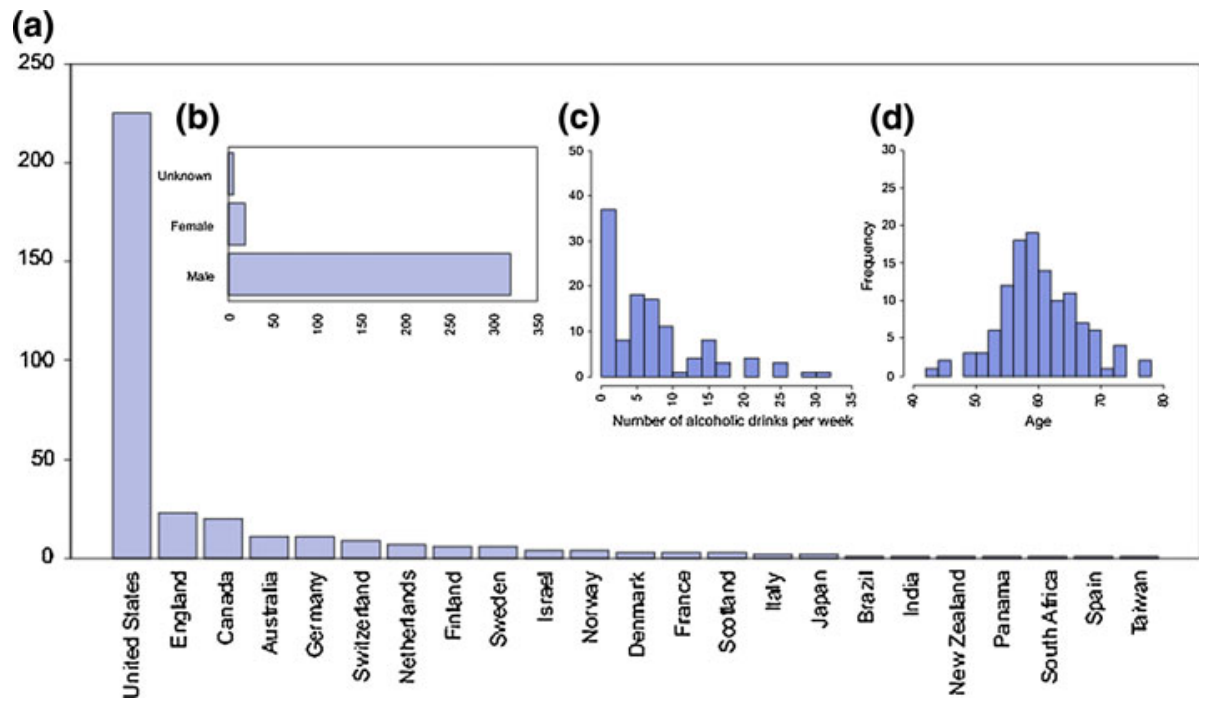

Fig. 1 Geographic distribution, demographic characteristics, and lifestyle choices

use first initials when publishing, an assumption rendered questionable by recent research (Tregenza 2002), they would only account for $7.2 \%$ of all highly cited researchers.

On average, respondents reported drinking around seven (7.17) alcoholic beverages per week, or about 2.5 more drinks per week than the average American (Gallup 2006). The total number of reported drinks ranged from 0 to 31 . The distribution of values for this variable are highly skewed, however, with greater than 50\% consuming six or fewer drinks per week, $20 \%$ drinking 14 or more drinks per week, and around 10\% drinking from 21 to 31 drinks per week. Compared to the median levels of alcohol consumption reported by Grim, our sample drinks three times more (156 oz pure alcohol/year) than his sample of Moravian ecologists ( $\sim 52 \mathrm{oz}$ pure alcohol/year) and more than half as much as his sample of Bohemians ( $282 \mathrm{oz}$ pure alcohol/year). (See Appendix 1 for calculations used to determine pure alcohol consumption.)

Respondents were slightly more than 61 years old on average, with values ranging from 43 to 79 years. The great majority $(80 \%)$ were between the ages of 55 and 70 years. Of the remainder, only $2.5 \%$ were under $50,80 \%$ from 50 to 54 years old, and $11.5 \%$ were 71 years or older.

Work habits and resources

We asked respondents about their laboratory size and structure, the amount of time spent on various work tasks, and levels of extramural funding (Fig. 2a-c). Most respondents $(82 \%)$ had their own laboratory, with an average size of 11 (10.98) individuals, and a range of 1 (in addition to the lab head) to 39 lab members. Labs were comprised on average of 4.2 graduate students, 2.7 undergraduates, 2.11 postdoctoral researchers, and 1.8 technicians. These number are somewhat inflated by the existence of a few big laboratories. Median values for each category of researcher $(3.5,2,1.5$, and 1 , respectively) better indicate the central tendencies of this variable. 

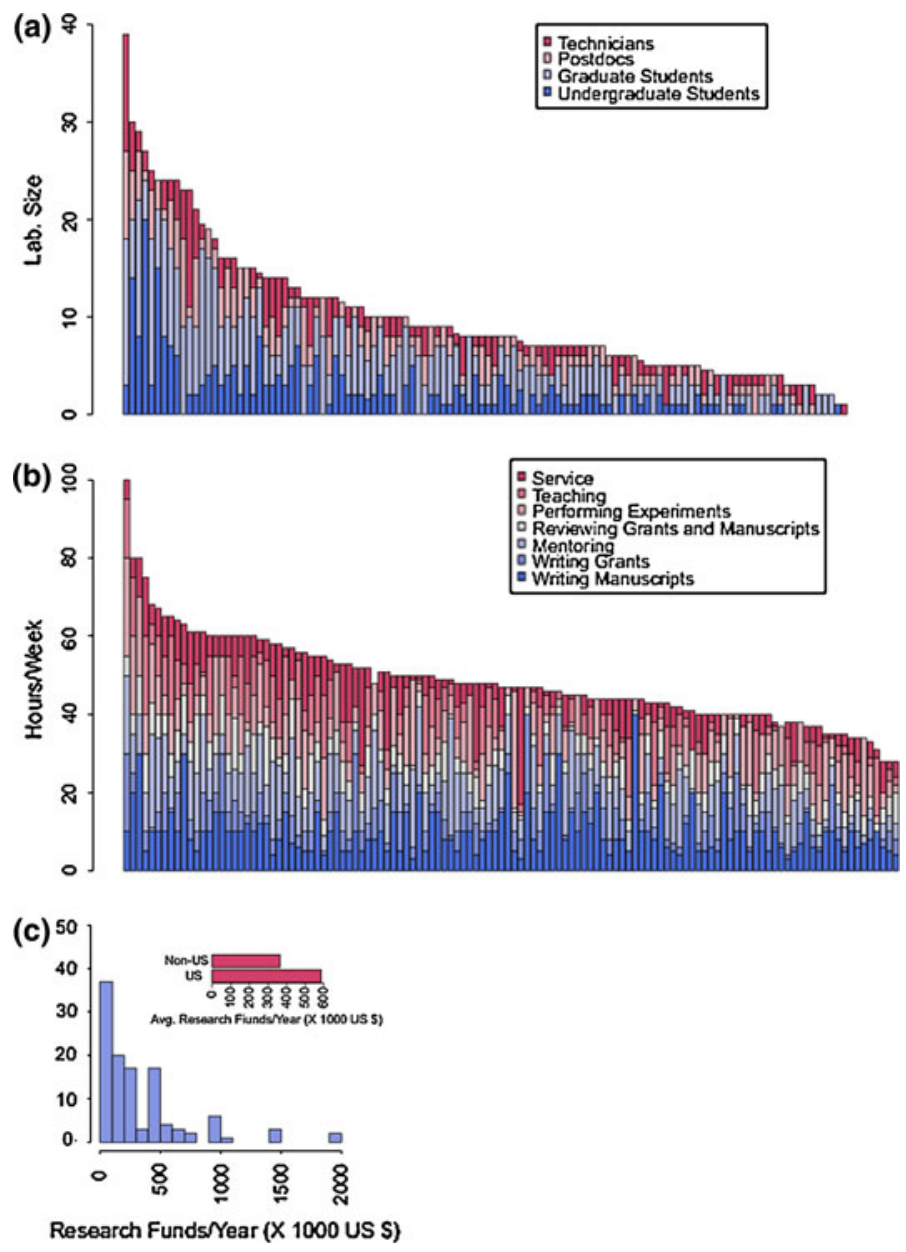

Fig. 2 Work habits and resources

On average, respondents spend slightly more time on service related ( $25.57 \mathrm{~h} /$ week) compared to research activities $(23.51 \mathrm{~h} /$ week). Most time was spent writing academic manuscripts $(10.17 \mathrm{~h})$, mentoring students and postdoctoral researchers $(9.26 \mathrm{~h})$, and conducting analyses and experiments $(7.99 \mathrm{~h})$. About equal amounts of time were spent teaching $(5.74 \mathrm{~h})$, in other 'service' related activities $(5.55 \mathrm{~h})$, reviewing manuscripts and grants $(5.02 \mathrm{~h})$, and grant writing $(4.82 \mathrm{~h})$. The average amount of time spent across all seven tasks was $48.52 \mathrm{~h}$, slightly less than doctoral level academics in biological and agricultural sciences generally (48.5 h compared to 52; Hoffer and Grigorian 2005). We regressed total number of hours worked and the proportion of time spent on research activities on respondent's age to test if older scientists were more likely to work fewer hours and to shift to service related activities. Neither relationship was significant.

The average annual levels of extramural funding received by respondents varied considerably, with an average of $\$ 387,909$ and values ranging from 0 to 4 million dollars. Fifty percent of respondents receive $\$ 250,000$ or less each year, and $81 \%$ receive $\$ 500,000$ or less. Only $6 \%$ report average levels of extramural funding equal to or exceeding 
$\$ 1,000,000$. The average funding levels for U.S. scientists was $\$ 534,594$ compared to $\$ 335,907$ for all other nations. We regressed total extramural funding on respondent's age to test if more senior scientists were less well funded. This relationship was not significant. (See Appendix 1 for information on conversion rates.)

Research foci, perspectives on citations and experiences with peer review

We asked respondents' about the types of research projects they prefer to work on, citations as indicators of scientific quality, their degree of research specialization (Fig. 3a-e), and their experiences with the peer review (Fig. 4a-c). On a scale of one (strongly disagree) to five (strongly agree), respondents prefer projects driven by theoretical concerns (3.57) significantly more than those driven by the potential for social benefits (3.06; $p=0.000$ ). On average, respondents neither agreed nor disagreed that citations accurately gauge publication quality (3.1), though the modal response was one of agreement. They were more apt to agree that their most highly cited papers are also their most significant contributions to the field (3.53). Respondents generally disagreed with the assertion that their research focused on a single set of questions or issues (2.12), with most disagreeing strongly.

Respondents reported that on average $71 \%$ of their manuscripts are accepted in their journal of first choice, with most reporting acceptance rates between 75 and 100\%. They have about one out of every two of their papers (0.58) rejected on average prior to publication. The distribution for this variable was highly uneven, however, with peak values around $0.2,0.5$ and 1 . On average, the greatest number of rejections respondents reported having had a manuscript receive prior to final publication was 2.54 .

\section{a Strongly Disagree \\ o Disagree \\ $\square$ Neither \\ व Agree \\ Strongly Agree}

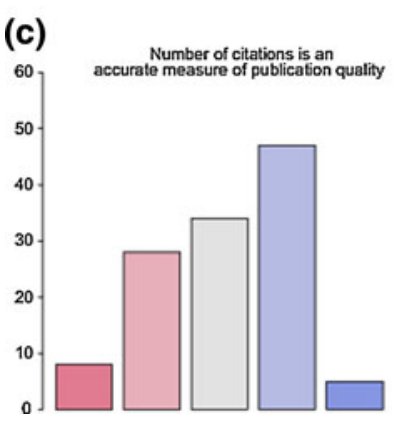

(a)

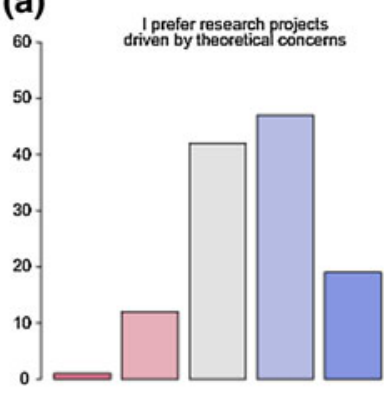

(d)

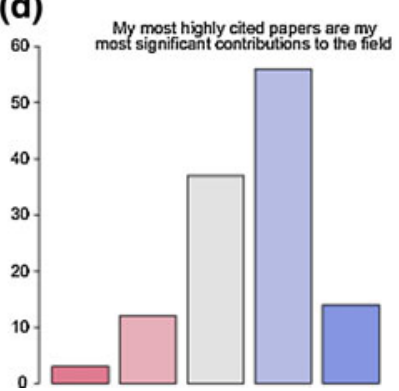

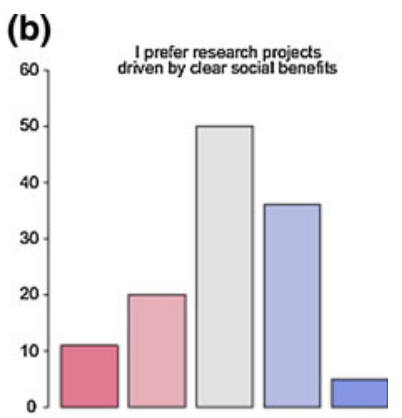

(e)

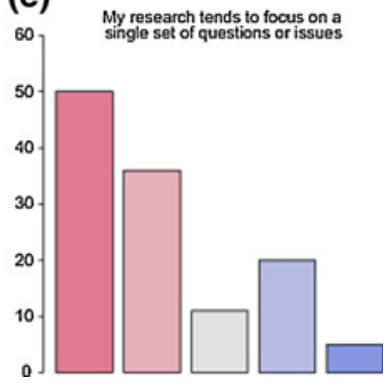

Fig. 3 Research foci and experiences with peer review 


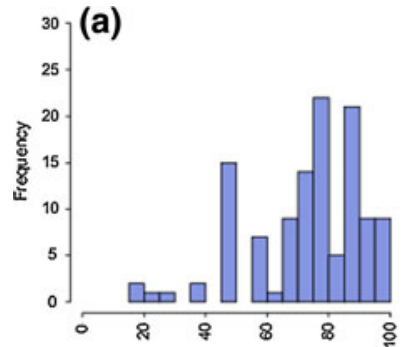

Fraction of manuscripts in frst choice joumal $(x 100)$
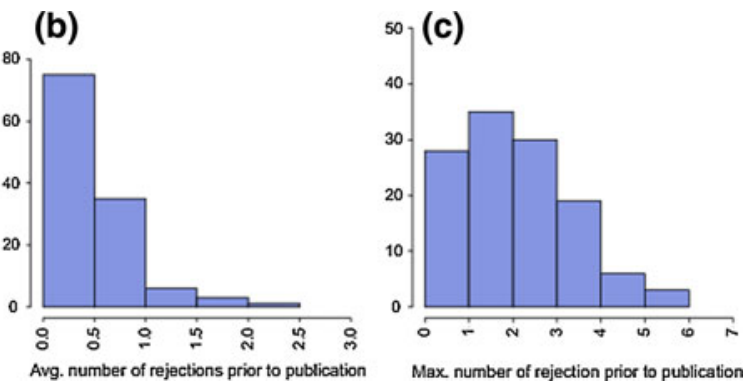

Fig. 4 Experiences with peer review

\section{Discussion}

This study examined the social characteristics of highly cited environmental scientists and ecologists by using survey data to test a set of well-grounded predictions based on past research. In some cases our predictions were supported. In others cases, particularly with respect to lifestyle choices, work habits, resources, research foci and opinions regarding citations, they were not, revealing findings which are both novel and surprising.

Geographically, highly cited environmental scientists and ecologists are based almost exclusively in North America and Western Europe. This mirrors McIntosh's (1989) finding that most "citation classics" authors in ecology were from North America and Western Europe, and other studies demonstrating dense concentrations of highly cited scientists in these regions more generally. This trend may be explained in part by geographic accumulative advantage, as citations originate more frequently from institutions located in the same country as cited authors than would be expected by chance (Pasterkamp et al. 2007). The migration of talented scientists from other areas to these regions is also a likely contributor (Ioannidis 2004). Whatever the reason, the probability of non-Western researchers in these fields becoming highly cited during this period is almost zero.

In terms of gender, the vast majority of highly cited environmental scientists and ecologists are men. This corroborates past research indicating that females tend to publish less than male colleagues (Cole and Zuckerman 1984; Fox 1983; Long 1987, 1992), a finding confirmed among ecologists (Primack and O'Leary 1989; Symonds et al. 2006). Hypothesized explanations range from differential familial obligations borne by women to gender discrimination to greater levels of research specialization among men leading to increased productivity (Wenneras and Wold 1997; Long and Fox 1995; Leahey 2006, 2007). However, this finding appears to contradict research on other disciplines finding that while women produce less research, it tends to be more highly cited (Cole and Zuckerman 1984; Long 1992).

As expected, most respondents are between the ages of 50 and 70, indicating that they are in middle to late career stage. This is in accordance with previous research finding that highly cited research tends to be published in earlier career stages (Garfield 1981; Falagas et al. 2008). However, the fact that every one of the top 10 most highly cited scientists in the area of environmental science and ecology in the period 1997-2007 was also one of the most highly cited scientists in this area during the period 1981-1999 (Thompson Scientific 2007) appears to indicate that at least some of these researchers remain highly cited over long time periods. This finding may also be in part an artifact of older scientists having on 
average greater numbers of older papers, thus increasing their chances of becoming highly cited.

Our findings regarding alcohol consumption are surprising. Though a fifth of the group does not drink, most drink more than Americans do generally. Furthermore, greater than $54 \%$ consume 10 or more alcoholic beverages a week, $20 \%$ consume 12 or more drinks per week, and $10 \%$ consume 21 or more drinks per week. Though national differences in drinking habits make direct comparisons between these groups difficult, the fact that our sample is both much more productive and much more highly cited, and drinks three times more alcohol than the less productive, less frequently cited group used in Grim's comparison (i.e. Moravians) does give rise to pause, suggesting the need for more and better information before a firm link between alcohol consumption and scientific accomplishment can be established. Certainly much more attention needs to be paid to possible intermitting variables which may make this relationship appear stronger than it is in fact, particularly given evidence indicating the opposite relationship between beer consumption, scientific productivity, and scientific quality at national levels (Lortie 2009).

In contrast to our expectation that these researchers would enjoy consistently high levels of extramural funding and have large laboratories, substantial differences exist in these areas, demonstrating a high degree of resource stratification even within this elite group. While some variance is to be expected, the degree of divergence is surprising, with some respondents having no laboratory and some no extramural funding. These marked differences may be in part due to sub-field differences in the amount of resources required to conduct highly cited research. For instance, theoretical ecologists or those synthesizing secondary ecological data sources to glean broad-scale patterns and processes require few assistants and little funding. National differences in research funding are also likely contributors to this pattern of inequality, with scientists in some countries conducting high quality work with fewer resources. Further, some researchers may produce a few 'breakout' papers in an otherwise average career characterized by modest funding levels. Still, average funding levels are high overall compared to others working in these research areas and laboratories larger than typical. While impossible to determine the direction of the relationship between resources and citation frequency, it is likely that initially high resource levels (both intellectual and material) contribute to greater recognition, in turn enhancing later resource acquisition (i.e. the Matthew Effect, Merton 1968). That average funding levels are unrelated to respondent's age indicates that these resource inequalities are being driven by other intervening factors.

Assuming the job tasks examined comprise the majority of their work, our sample works slightly fewer hours on average than do doctoral level academics in the biological and agricultural sciences. This is indeed surprising, perhaps indicating differences in the time spent on specific job facets to be a better predictor of being highly cited than total work hours. For instance, academics spending the majority of their time teaching as opposed to publishing will almost certainly be less cited. It may also be that highly cited scientists have accumulated enough scientific capital early in their careers (e.g. access to data, expert collaborators, funds, technical skills, etc.) to allow them to outperform others though they work fewer hours in later career stages (thus benefiting from accumulative advantage). That age is unrelated to number of hours worked may also indicate that all members of this group have passed an age threshold or career stage beyond which they work less. However, testing these assumptions is impossible given existing data. Also contrary to expectations, these researchers spend slightly more time on service related as compared to research activities, and the proportion of time spent on research activities was unrelated to respondent's age. Again, it may be that on the whole members of this group 
have moved out of active research and onto noblesse oblige, and that once this point has been reached incremental additions of age matter little. Alternately, this group may differ in important ways from the ultra-elites (i.e. Nobel Prize winners) examined in previous research.

As predicted, these highly cited scientists also prefer research problems driven by theoretical concerns over those with potential societal benefits. This makes sense as research addressing broad theoretical concerns is likely to be of interest to greater numbers of researchers than work on specific social issues, thus garnering large numbers of citations. Data further indicate that while highly cited scientists are ambivalent regarding to the extent to which citations indicate quality generally, they tend to agree that they are accurate indicators of quality for their own work. This differs from past research finding that more highly cited scientists tend to believe that citations accurately measure scientific quality (Hargens and Schuman 1990), but confirms work by Aksnes (2006) showing that authors' assessments of their work correspond reasonably well with the citations counts which their work receives. Members of our sample strongly disagree with the assertion that they maintain a narrow research focus. While contradicting work demonstrating links between specialization and productivity, this finding corresponds with work in the psychology of science indicating that highly creative people tend to range widely in their intellectual pursuits, with only some work receiving recognition (Simonton 1984, 1988). Not surprisingly, these scientists are highly successful in navigating the peer review system, publishing most of their work in their journal of first choice and receiving few rejections.

In many respects the social characteristics of highly cited researchers in environmental science and ecology appear to reflect broader patterns of global inequality. Highly cited environmental scientists and ecologists tend to work in the wealthiest areas of the world with the greatest numbers of universities and highest levels of educational funding. While determining the exact mechanisms driving these inequalities is impossible given our data, it seems clear that the most highly cited scientists in these fields tend to hail from the most materially and culturally privileged nations and social groups. This in no way diminishes the significance of these individuals' achievements and sacrifices, but does imply that such privilege is a necessary (but insufficient) condition upon which such achievements are typically predicated. It further implies that most of the world's potential scientific talent remains untapped.

It is also interesting that in other respects this group of researchers is highly heterogeneous. The amount of time spent on research and devoted to different job tasks varies considerably, as do the size and structure of their laboratories and their annual levels of extramural funding. Furthermore, while some imbibe copious amounts of alcohol others abstain. That these researchers differ significantly along these dimensions but are all highly cited suggests the potential for multiple pathways to becoming highly cited. More research is needed to understand the specific avenues and methods by which researchers achieve this elite status.

Several caveats must be borne in mind with regards to research on highly cited scientists. First, it is difficult to know with precision which social factors are associated with the production of highly cited research in the absence of a meaningful comparison group. More data is needed on the social characteristics of scientists generally. Second, because of the time it takes for citations to accrue, highly cited scientists can only be identified after the fact. While highly cited scientists tend to remain highly cited, explorations of the conditions that led to initial success are challenging. Third, evidence about any group of highly cited scientists is always specific to the discipline and time period under 
consideration. Citations patterns change over time and differ across disciplines. For this reason gathering detailed information on highly cited scientists at as fine a disciplinary and temporal resolution as possible is imperative. Future researchers would do well to develop comparable measures for non-highly cited scientists, to gather comparative data on other disciplines, and examine citation patterns at finer temporal resolution. Such considerations would go a long way in furthering understanding about the social characteristics of highly cited scientists and the conditions under which highly cited research is produced.

Open Access This article is distributed under the terms of the Creative Commons Attribution Noncommercial License which permits any noncommercial use, distribution, and reproduction in any medium, provided the original author(s) and source are credited.

\section{Appendix 1}

1. Journals included in Thompson ISI's "Environmental Science and Ecology" category A full list of journals included in this category can be accessed at http://www. isihighlycited.com/isi_copy/Comm_newse04EVD.htm.

2. Topical areas covered by journals in "Environmental Science and Ecology"

This area includes journals dealing with biodiversity conservation; climate change; pure and applied ecology; ecological modeling and engineering; ecotoxicology; evolutionary ecology; environmental contamination and toxicology; environmental health, monitoring, technology, geology, and management; natural history; soil science and conservation; and water resources research and engineering.

3. Calculating alcohol consumption

Number of alcoholic beverages was figured by converting all responses to the American standards, where one glass of wine is four ounces and one beer twelve ounces.

To compare with data presented by Grim (2008), number of drinks was converted into pure alcohol consumption using the standard metric of $0.5 \mathrm{oz}$ of pure alcohol per onefour ounce glass of wine and one twelve ounce glass of beer. No respondent reported hard alcohol consumption.

4. Annual funding

December, 2009 exchange rates were used when converting foreign currencies into U.S. Dollars.

\section{Appendix 2}

The survey takes approximately $10 \mathrm{~min}$ to complete. We realize that your time is extremely valuable, and thank you in advance for your consideration. Very little is known about highly cited researchers, and therefore each response to this survey is valuable.

1. Please enter your first and last name here. This is strictly confidential and only used to avoid reminders.

2. How many hours per week do you spend on the following activities?
(A) Writing academic manuscripts
(B) Writing grants
(C) Mentoring students and postdoctoral researchers 
(D) Reviewing manuscripts and grants

(E) Conducting experiments/analyses

(F) Teaching

(G) Committee work

3. On average, how much extramural funding do you receive annually?

4. If you have a lab, please report the average number of individuals working in the following capacities per year.
(A) Undergraduates
(B) Graduates
(C) Postdoctoral researchers
(D) Technicians

5. Please report your experiences with the peer review system.
(A) On average, how many times do your manuscripts get rejected prior to publication?
(B) What is the greatest number of rejections you have had on a paper prior to final acceptance?
(C) What percentage of your manuscripts get accepted in your journal of first choice?

6. To what extent do you agree with the following statements? $(1=$ strongly disagree, $2=$ disagree, $3=$ neither agree nor disagree, $4=$ agree, $5=$ strongly agree)
(A) My research tends to focus on a single set of questions or issues.
(B) My most cited papers are my most significant contributions to the field.
(C) Number of citations is an accurate measure of citation quality.
(D) I prefer research projects driven by clear social benefits.
(E) I prefer research projects driven by theoretical concerns.

7. Recent research indicates that there is a correlation between alcoholic consumption and scientific productivity. On average, how many alcoholic drinks do you consume per week?

\section{References}

Aksnes, D. W. (2006). Citation rates and perceptions of scientific contribution. Journal of the American Society for Information Science and Technology, 57(2), 169-185.

Basu, A. (2006). Using ISI's 'Highly cited researchers' to obtain a country level indicator of citation excellence. Scientometrics, 68(3), 361-375.

Batty, M. (2003). The geography of scientific citation. Environment and Planning A, 35, 761-765.

Cole, J. R., \& Cole, S. (1973). Social stratification in science. Chicago: University of Chicago Press.

Cole, J. R., \& Zuckerman, H. (1984). The productivity puzzle: Persistence and change in patterns of publication of men and women scientists. In M. W. Steinkamp \& M. L. Maehr (Eds.), Advances in motivation and achievement (pp. 217-256). Greenwich, CT: JAI Press.

Collins, R. (1998). The sociology of philosophies: A global theory of intellectual change. Cambridge: Harvard University Press.

Dennis, W. (1955). Variations in productivity among creative workers. Scientific Monthly, 80, 277-278.

Falagas, M. E., Ierodiakonou, V., \& Alexiou, V. G. (2008). At what age do biomedical scientists do their best work? Journal of the Federation of American Societies for Experimental Biology. Accessed June 9, 2009, from http://www.fasebj.org/cgi/rapidpdf/fj.08-117606v1.pdf. 
Fox, M. F. (1983). Publication productivity among scientists: A critical review. Social Studies of Science, 13, 285-305.

Gallup Organization. (2006). Consumption Habits Poll, conducted July 6-9, 2006. News release, Gallup Poll News Service.

Garfield, E. (1973). More on forecasting Nobel Prizes and the most-cited scientists of 1972! Current Contents No, 40, 5-7.

Garfield, E. (1981). The 1000 contemporary scientists most-cited 1965-1978. Part 1. The basic list and introduction. Current Contents, 41, 5-14.

Garfield, E. (1992). Of Nobel class, women in science, citation classics, and other essays. Current Contents, $35,3-12$.

Garfield, E., \& Malin, M. V. (1968, December 26-31). Can Nobel Prize winners be predicted? Paper presented at the 135th meetings of the American Association for the Advancement of Science, Dallas, TX.

Grim, T. (2008). A possible role of social activity to explain differences in publication output among ecologists. Oikos, 117(4), 484-487.

Hackett, E. J. (2005). Essential tensions: Identity, control and risk in research. Social Studies of Science, 35(5), 787-826.

Hagstrom, W. O. (1965). The scientific community. New York: Basic Books.

Hargens, L. L., \& Schuman, H. (1990). Citation counts and social comparisons: Scientists' use and evaluation of citation index data. Social Science Research, 19(3), 205-221.

Hermanowicz, J. (1998). The stars are not enough: Scientists-their passions and professions. Chicago: University of Chicago Press.

Hermanowicz, J. (2005). Classifying universities and their departments: A social world perspective. Journal of Higher Education, 61(1), 26-55.

Hoffer, T. B., \& Grigorian, K. (2005). All in a week's work: Average work weeks of doctoral scientist and engineers. Arlington, VA: National Science Foundation.

Ioannidis, J. P. A. (2004). Global estimates of high-level brain drain deficit. The FASEB Journal, 18, 936939.

Kuhn, T. (1962). The structure of scientific revolutions. Chicago, IL: University of Chicago Press.

Kuhn, T. (1977). The essential tension: Selected studies in scientific tradition and change. Chicago: University of Chicago Press.

Leahey, E. (2006). Gender differences in productivity: Research specialization as a missing link. Gender and Society, 20(6), 754-780.

Leahey, E. (2007). Not by productivity alone: How visibility and specialization contribute to academic earnings. American Sociological Review, 72(4), 533-561.

Leahey, E., Crockett, J. L., \& Hunter, L. A. (2008). Gendered academic careers: Specializing for success. Social Forces, 85(3), 1273-1309.

Long, J. S. (1987). Problems and prospects for research on sex differences in the scientific career. In L. S. Dix (Ed.), Women: Their underrepresentation and career differentials in science and engineering (pp. 157-169). Washington, DC: National Academy Press.

Long, J. S. (1992). Measures of sex differences in scientific productivity. Social Forces, 71(1), 159-178.

Long, J. S., \& Fox, M. F. (1995). Scientific careers: Universalism and particularism. Annual Review of Sociology, 21, 45-71.

Lortie, C. J. (2009). Letter to the editor: A global comment on scientific publications, productivity, people, and beer. Scientometrics. doi:10.1007/s11192-009-0077-z.

Lotka, A. (1926). The frequency distribution of scientific productivity. Journal of the Washington Academy of Sciences, 16(12), 317-324.

MacRoberts, M. H., \& MacRoberts, B. R. (1986). Quantitative measures of communication in science. A study of the formal level. Social Studies of Science, 16, 151-172.

MacRoberts, M. H., \& MacRoberts, B. R. (1996). Problems of citation analysis. Scientometrics, 36, 435444.

McIntosh, R. P. (1989). Citations classics of ecology. The Quarterly Review of Biology, 64(1), 31-49.

Merton, R. K. (1968). The Matthew effect in science. Science, 159(3810), 56-63.

Pasterkamp, G., Rotmans, J. I., De Kleun, D. V. P., \& Borst, C. (2007). Citation frequency: A biased measure of research impact significantly influenced by the geographical origin of research articles. Scientometrics, 70(1), 153-165.

Price, D. J. S. (1963). Little science, big science. New York: Columbia University Press.

Primack, R. B., \& O'Leary, V. E. (1989). Research productivity of men and women ecologists: A longitudinal study. Bulletin of the Ecological Society of America, 70, 7-12. 
Sills, S. J., \& Song, C. (2002). Innovations in survey research: An application of web surveys. Social Science Computer Review, 20, 22-30.

Simonton, D. K. (1984). Genius, creativity and leadership: Historiometric inquiries. Cambridge: Harvard University Press.

Simonton, D. K. (1988). Scientific genius: A psychology of science. Cambridge: Cambridge University Press.

Small, H. (2004). Why authors think their papers are highly cited. Scientometrics, 60, 305-316.

Smith, L. C. (1981). Citation analysis. Library Trends, 30, 83-106.

Symonds, M. R. E., Gemmell, N. J., Braisher, T. L., Gorringe, K. L., \& Elgar, A. E. (2006). Gender differences in publication output: Towards an unbiased metric of research performance. PLoS ONE, 1(1), e127.

Thompson Scientific. (2007). Most cited researchers in environment and ecology (1997-2007). Accessed March 1, 2010, from http://in-cites.com/top/2007/fourth07-env.html.

Tregenza, T. (2002). Gender bias in the refereeing process? Trends in Ecology \& Evolution, 17(8), 349-350.

Trifunac, M. D. (2006). On citation rates in earthquake engineering. Soil Dynamics and Earthquake Engineering, 36, 1049-1062.

Warner, J. (2000). A critical review of the application of citation studies to the research assessment exercises. Journal of Information Science, 26(6), 453-460.

Wenneras, C., \& Wold, A. (1997). Nepotism and sexism in peer-review. Nature, 387, 341-343.

Zuckerman, H. (1996). Scientific elite. New Brunswick: Transaction Publishers. 